Diagnostic Accuracy Study Protocol

\title{
$\Theta$ Protocol for Accuracy of Point of Care (POC) or In-Office Urine Drug Testing (Immunoassay) in Chronic Pain Patients: A Prospective Analysis of Immunoassay and Liquid Chromatography Tandem Mass Spectometry (LC/MS/MS)
}

Laxmaiah Manchikanti, MD, Yogesh Malla, MD, Bradley W. Wargo, DO, Kimberly A. Cash, RT

Vidyasagar Pampati, MSc, Kim S. Damron, RN, Carla D. McManus, RN, BSN, and Doris E. Brandon, CST

From: Pain Management Center of Paducah Paducah, KY

Author affiliation information is on page: E13.

Address correspondence: Laxmaiah Manchikanti, MD

2831 Lone Oak Road Paducah, Kentucky 42003

E-mail:

drlm@thepainmd.com

Disclaimer: The study is conducted by the Pain Management Center of Paducah and the Ambulatory Surgery Center. It is sponsored by Millennium Laboratories,

16981 Via Tazon, Suite

F, San Diego, CA 92127.

Sponsorship includes

equipment supplies and

expenses. The authors

received no honorarium or reimbursement.

Conflict of interest: None.

Manuscript received: 12/05/2009

Revised manuscript

received: 12/27/2009 Accepted for publication: 01/05/2010

Free full manuscript: www. painphysicianjournal.com
Background: Therapeutic use, overuse, abuse, and diversion of controlled substances in managing chronic non-cancer pain continues to be an issue for physicians and patients. It has been stated that physicians, along with the public and federal, state, and local government; professional associations; and pharmaceutical companies all share responsibility for preventing abuse of controlled prescription drugs. The challenge is to eliminate or significantly curtail abuse of controlled prescription drugs while still assuring the proper treatment of those patients. A number of techniques, instruments, and tools have been described to monitor controlled substance use and abuse. Thus, multiple techniques and tools available for adherence monitoring include urine drug testing in conjunction with prescription monitoring programs and other screening tests. However, urine drug testing is associated with multiple methodological flaws.

Multiple authors have provided conflicting results in relation to diagnostic accuracy with differing opinions about how to monitor adherence in a non-systematic fashion. Thus far, there have not been any studies systematically assessing the diagnostic accuracy of immunoassay with laboratory testing.

Study Design: A diagnostic accuracy study of urine drug testing.

Study Setting: An interventional pain management practice, a specialty referral center, a private practice setting in the United States.

Objective: To compare the information obtained by point of care (POC) or in-office urine drug testing (index test) to the information found when all drugs and analytes are tested by liquid chromatography tandem mass spectroscopy (LC/MS/MS) reference test in the same urine sample.

Methods: The study is designed to include 1,000 patients with chronic pain receiving controlled substances.

The primary outcome measure is the diagnostic accuracy. Patients will be tested for various controlled substances, including opioids, benzodiazepines, and illicit drugs.

The diagnostic accuracy study is performed utilizing the Standards for Reporting of Diagnostic Accuracy Studies (STARD) initiative which established reporting guidelines for diagnostic accuracy studies to improve the quality of reporting. The prototypical flow diagram of diagnostic accuracy study as described by STARD will be utilized.

Results: Results of diagnostic accuracy and correlation of clinical factors in relation to threshold levels, prevalence of abuse, false-positives, false-negatives, influence of other drugs, and demographic characteristics will be calculated.

Limitations: The limitations include lack of availability of POC testing with lower cutoff levels.

Conclusion: This article presents a protocol for a diagnostic accuracy study of urine drug testing. The protocol also will permit correlation of various clinical factors in relation to threshold levels, prevalence of abuse, false-positives, false-negatives, influence of other drugs, and demographic characteristics.

Clinical Trial Registration: NCT 01052155

Key words: Controlled substances, opioids, benzodiazepines, illicit drugs, abuse, diversion, adherence monitoring, prescription monitoring programs

Pain Physician 2010; 13:E1-E22 
n recent years, the expanded use of opioid analgesics for the treatment of chronic noncancer pain, and the introduction of high-dose, extended-release opioid formulations have both improved access to these drugs and increased misuse, abuse, and diversion (1-18). Federal, state, and local governments; professional associations; as well as pharmaceutical companies, physicians, and the public all share responsibility for preventing abuse of controlled prescription drugs (6). The challenge is to eliminate or significantly curtail abuse of controlled prescription drugs while still assuring the proper treatment of those patients who can be helped by these medications. Consequently it is crucial to 1) allow accurate clinical and administrative (i.e., legal and governmental) assessment of the true nature and scope of prescription (and illicit) drug abuse, 2) provide physicians' insight to patients' patterns of drug use and compliance so as to direct the type and conduct of treatment that can and should be provided, and thus 3 ) insure the safe, ethical, and legally sound practice of medicine. Adherence monitoring has been shown to be a useful approach to acquiring information from biological, psychological, and social domains that can assist in identifying and/or predicting patterns of drug use, compliance, misuse, and abuse $(2,14)$.

\subsection{Introduction}

A number of techniques, instruments, and tools have been described to monitor controlled substance use and abuse. Given that multiple factors may be involved in drug misuse and abuse, no single instrument or assessment method has universal evaluative or predictive utility. Thus, multiple techniques and tools are available and have been used to monitor adherence. These include various screening tests, urine drug testing, and prescription monitoring programs. Each of these methods has some relative validity and utility in assessing patterns of drug use, misuse, abuse, and/or the potential or occurrence of addiction. In the majority of cases, collective application of all instruments with clinical judgment is essential.

\subsection{Urine Drug Testing}

Currently, the use of biological sample screening to detect drug levels enjoys utility as a method 1) to detect the presence of opioids and other drugs prior to, and/or at the beginning of, treatment that may be indicative of (patterns/extent of) previous and current drug use; 2) to establish relative baselines from which treatment compliance may be evaluated, and/or 3) to suggest/indicate illicit drug use.

One of the simplest, most non-invasive approaches to biological sample screening is analysis of urine for drugs and their metabolic products. While drug testing may be performed by either testing the urine, serum, or hair, urine drug testing is regarded as the gold standard. This is primarily because urinary assay allows for the presence or absence of certain drugs to be evaluated with (relatively) good specificity, sensitivity, ease of administration, and cost. However, controversies exist regarding the clinical value of urine drug testing, partly because most current methods are designed for, or adapted from, forensic or occupational deterrentbased testing for illicit drug use and are not entirely optimal for applications in the chronic pain management setting. Yet, with appropriate consideration of the caveats against misinterpretation (arising from limits of specificity, and/or false-positive or false-negative screens), urine drug testing can be a useful tool to aid in both the ability to evaluate patients' compliance with prescribed regimens of controlled substances and to diagnose the misuse or abuse of prescribed drugs or use of illicit agents.

The term "urine drug screening" is actually a misnomer, since it implies a generic screening for any and all drugs; it is impossible to prove the presence or absence of all drugs. There is not a standard "urine drug test" that is suitable for all purposes and settings. However, there are numerous types of urine analyses that physicians can employ to meet their clinical needs (19-28).

Urine drug testing is a useful tool in managing chronic pain patients that are treated with controlled substances (22). As matter of fact, urine drug testing is becoming a routine practice in chronic pain management settings (22-28). In addition to becoming a routine test, urine drug testing has been used, misused, and abused with financial incentives and influence of external forces including economic incentives along with medical licensure boards, Drug Enforcement Agency (DEA), and other governmental agencies. Urine drug testing is most commonly used for 2 purposes. First, is to detect the presence of prescribed medications (i.e., compliance testing) and second is to identify substances that are not expected to be present in the urine (e.g., non-prescription and illicit drugs, i.e., forensic testing).

Compliance testing is extremely useful as the physician is looking for the presence of prescribed medications as evidence of their appropriate use. Positive results indicate appropriate use and also compliance with 
the treatment plan, and absence of prescribed drugs or finding non-prescribed or illicit drugs are concerning and mandate further evaluation and management.

\subsection{Urine Drug Testing Methods}

There are typically 2 types of urine drug testing. These include immunoassay drug testing (either laboratory-based or office-based, the latter being colloquially referred to as "dipstick testing") and laboratory-based specific drug identification utilizing gas chromatographic/mass spectroscopy (GC/MS), high performance liquid chromatography (HPLC) or liquid chromatography tandem mass spectroscopy (LC/MS/MS). The combination of these testing methods can ensure accuracy and improve efficacy, yet using both may be costly. The method used is dependent on the reason(s) for and desired sensitivity of the test. Immunoassay drug tests are designed to determine the presence or absence of particular substances according to a predetermined threshold, and are the most common methods utilized. However, identification of a specific drug may be needed, and this mandates the use of GC/MS or LC/MS/MS.

\subsection{Methodological Issues in Urine Drug Testing}

Immunoassays are based on the principle of competitive binding, and use antibodies to detect the presence of a particular drug or metabolite in a urine sample. Immunoassay drug testing is provided either in the laboratory or by means of rapid drug testing at the point of service. The capability of a particular immunoassay to detect drugs can vary according to both the drug concentration in the urine and the assay's cut-off concentration. Any indication of a drug above the cutoff is deemed to be positive, and any response below the cut-off is negative. However, almost all immunoassays are subject to cross-reactivity. For example, while tests for cocaine are highly predictive of cocaine use, tests for amphetamine/methamphetamine are highly cross-reactive, and may detect other sympathomimetic amines (e.g., ephedrine and pseudoephedrine) and therefore are frequently unreliable and may lack predictive or diagnostic value. Standard tests for opiates are very responsive for morphine and codeine, but cannot distinguish which specific substance is present, nor can it distinguish between their metabolites. As well,

Table 1. Urine drug testing: Typical screening and confirmation cut-off concentrations and detection times for drugs of abuse.

\begin{tabular}{|c|c|c|c|c|c|}
\hline Drug & $\begin{array}{c}\text { Screening } \\
\text { cut }- \text { off } \\
\text { concentrations } \\
\text { ng/mL urine }\end{array}$ & $\begin{array}{l}\text { Analyte tested in } \\
\text { confirmation }\end{array}$ & $\begin{array}{c}\text { Confirmation cut - } \\
\text { off concentrations } \\
\text { ng/mL } \\
(\text { non }- \text { regulated })\end{array}$ & $\begin{array}{c}\text { Confirmation } \\
\text { cut }- \text { off } \\
\text { concentrations } \\
\text { ng/mL } \\
\text { (federally } \\
\text { regulated) }\end{array}$ & Urine detection time \\
\hline Amphetamine & 1,000 & Amphetamine & 500 & 500 & $2-4$ days \\
\hline Barbiturates & 200 & $\begin{array}{l}\text { Amobarbital, secobar- } \\
\text { bital, other barbiturates }\end{array}$ & 200 & NA & $\begin{array}{l}2-4 \text { days for short acting; } \\
\text { up to } 30 \text { days for long acting }\end{array}$ \\
\hline Benzodiazepines & 200 & $\begin{array}{l}\text { Oxazepam, diazepam, } \\
\text { other benzodiazepines }\end{array}$ & 200 & NA & Up to 30 days \\
\hline Cocaine & 300 & Benzoylecgonine & 150 & 150 & $1-3$ days \\
\hline Codeine & 300 & Codeine, morphine & $300 ; 300$ & 2,$000 ; 300$ & $1-3$ days \\
\hline Heroin & 300 & $\begin{array}{l}\text { Morphine, } \\
6 \text { - acetylmorphine }\end{array}$ & $300 ; 10$ & 2,$000 ; 10$ & $1-3$ days \\
\hline Marijuana & $100 ; 50 ; 20$ & Tetrahydrocannabinol & 15 & 15 & $\begin{array}{l}1-3 \text { days for casual use; up } \\
\text { to } 30 \text { days for chronic use }\end{array}$ \\
\hline Methadone & 300 & Methadone & 300 & NA & $2-4$ days \\
\hline Methamphetamine & 1,000 & $\begin{array}{l}\text { Methamphetamine, } \\
\text { amphetamine }\end{array}$ & $500 ; 200$ & 1,500 & $2-4$ days \\
\hline Phencyclidine & 25 & Phencyclidine & 25 & 25 & $\begin{array}{l}2-7 \text { days for casual use; } \\
\text { up to } 30 \text { days for chronic } \\
\text { use }\end{array}$ \\
\hline
\end{tabular}

Source: Manchikanti L, et al. Monitoring opioid adherence in chronic pain patients: Tools, techniques, and utility. Pain Physician 2008; 11:S155S180 (22). 
these assays show a lower sensitivity for semisynthetic/ synthetic opioids (e.g., oxycodone, fentanyl, methadone, and buprenorphine), and therefore a negative response does not exclude use of these opioids.

In contrast to immunoassays or rapid drug testing, laboratory-based specific drug identification is both more sophisticated and more expensive. Laboratorybased specific drug identification is needed to confirm the presence of a given drug, and/or to identify drugs that cannot be isolated by screening test(s). Table $1 \mathrm{il}-$ lustrates cut-off levels for various drugs detected by urine analysis. In chronic pain management settings, a panel for rapid drug screening should ideally include opioids (including oxycodone and methadone) as well as benzodiazepines, barbiturates, marijuana, cocaine, amphetamines, and methamphetamines. In recent years, Ultram (Tramadol) as well as Soma (carisoprodol) are becoming an issue as they have been classified as controlled drugs in some states. There is no testing for Tramadol, and Carisoprodol may present as a barbiturate. If a custom panel is not available, multiple tests may be required as rapid drug screening(s). Detection times can vary considerably, depending upon acute versus chronic use, the particular drug used within a class, individual characteristics of the patient, and the method used to test for a substance. Since both falsenegatives and false-positives are possible, questionable results should always be followed by confirmatory or no-threshold laboratory testing prior to taking any action(s) (such as confronting the patient, altering treatment plans, etc.).

\subsection{Federally Regulated Testing}

Federally regulated testing is the most established use of urine drug testing - assaying 5 drugs in federal employees and federally regulated industries; marijuana, cocaine, opiates, PCP, and amphetamines/methamphetamines $(22,29)$. Positive results based on immunoassays alone are referred to as presumptive positives, because of the possibility for cross-reactivity, differing sensitivity, and variable specificity in given immunoassays (20). Consequently, results of federally regulated testing must be confirmed by a more specific method such as GC/MS or LC/MS/MS. Federally regulated testing methods are generally not applicable in most clinical pain management settings in light of the street sample and chain of custody requirements that are mandated in all federal testing. As well, the cut-off concentrations used in federally regulated testing (particularly the reference cut-off concentrations utilized for opioids) are too high to be of value in clinical practice.

\subsection{Non-Regulated Testing}

Non-regulated testing methods are more generally used in the clinical setting and can be customized to meet the specific needs incurred in individual practices (21). Non-regulated testing may be performed for legal purposes, including child custody cases, drivers' license revocation, criminal justice, insurance purposes, workers compensation, sports testing, and pre-employment screening or random workplace testing (30). In such instances these tests may require a chain of custody, provision of split samples, and secure storage of non-negative samples. Recently, urine drug testing has become more commonly used to screen middle and high school children participating in competitive sport activities (31). The scope of testing in these settings exceeds the federal 5 drugs and several other drugs are routinely assayed including methadone, propoxyphene, benzodiazepines, oxycodone, and barbiturates.

\subsection{Practical Aspects}

In clinical settings, urine drug testing is utilized for compliance, as well as forensic testing to monitor therapeutic activity, misuse, and illegal drug use (22). Consequently, the initial and confirmatory testing levels, as well as the number of drugs tested, can be customized and are usually different from those evaluated under federal testing programs. Table 1 illustrates typical detection times for urine drug testing of common drugs of abuse, cut-off levels, and comparison of federally regulated cut-off and concentration levels. As illustrated in the table, opioid cutoff levels in clinical settings are 300 ng per $\mathrm{mL}$, which allows for a considerably more sensitive assay than the 2,000 $\mathrm{ng}$ per $\mathrm{mL}$ that is employed in federal cut-off levels. Even then, arguments exist that cut-off levels should be much lower or that each test ought to be performed as a no threshold test.

\subsection{Caveats in Urine Drug Testing}

Drug screening can be an important tool to ensure patient compliance with prescription regimens. Drug screening or testing may be effectively performed in the physician's office using point of care (POC) urine (dipstick) immunoassay testing. However, practitioners using POC testing need to be aware of whether the system used is compliant with methods and assurances established by the Clinical Laboratory Investigative Association (CLIA). A CLIA waiver is required to perform certain tests (including urine immunoassay). Only im- 
munoassay tests for certain drugs are CLIA waived, and these may be performed in the office only if (and when) a certificate of waiver is first obtained by the physician or facility. Generally these tests do not require extensive training for office personnel. Unfortunately however, Medicare and other payors do not uniformly allow all CLIA-waived testing.

When considering the effectiveness, validity, and/ or viability of differing types of drug screens, a GC/MS or LC/MS/MS, that is mass spectrometric confirmed by an independent laboratory is most commonly regarded as the best (i.e., most sensitive) drug screen. Mass spectrometric measurements allow high quality, precise measures of a variety of drugs that are relevant to chronic pain management. Mass spectrometric analysis should be considered as a confirmatory test in those circumstances in which the initial urine drug screen findings would prompt a change in therapy. POC immunoassay tests are generally shown to be greater than $95 \%$ accurate if performed and interpreted correctly. Table 2 presents potential sources of drug screen cross reactivity. Toxicologists from laboratories performing mass spectrometric testing are readily available to discuss interpretation(s) of the results.

Additionally, the importance of understanding the validity of the sample cannot be understated. Urine can be altered; there are many commercially available urine samples or adulterants that can alter the validity of urine that is to be submitted to physicians and laboratories for testing. Fortunately, the vast majority of these reagents are unreliable or easily detected by common testing methods. Common techniques, such as commercially available "clean" urine samples, and/ or getting specimens from another individual are situations of which physicians need to be aware. If collected within 4 minutes, the temperature range of urine should be between $90^{\circ}$ and $100^{\circ} \mathrm{F}$; the $\mathrm{pH}$ should be between 4.5 and 8 , and the creatinine norm is $20 \mathrm{mg} /$ $\mathrm{dl}$ or greater. Dilute urine has $<20 \mathrm{mg} / \mathrm{dl}$ creatinine, while alien urine is $<5 \mathrm{mg} / \mathrm{dl}$. Significant variation from these standards should be regarded with some suspicion, and may suggest the need for reasonably prompt re-sampling.

Interpretation of drug screens must include knowledge of opioid metabolites. For example, a urine screen that is positive for hydromorphone in a patient receiving hydrocodone does not reflect drug abuse, but rather the appropriate metabolism of hydrocodone. Similarly, since codeine is metabolized to morphine, a screen that is positive for morphine in a patient taking codeine would be expected (32). Historically, there have been instances in which physicians who were not familiar with opioid metabolism have wrongly accused patients of drug abuse (Table 3). Thus, given the pain physicians' professional role and responsibilities (for expert knowledge and competence in practice), such errors are inexcusable. Physicians should establish a conservative, but firm policy regarding the response to a positive drug screen. First and foremost, the accuracy of the screen should be verified, and any potential sources of error identified (33). Consequently, when in doubt, it is advisable to repeat the screen as quickly as possible.

Table 2. Drug cross-reactants.

\begin{tabular}{|l|l||}
\hline \multicolumn{2}{|l||}{ Drug Cross-Reactants } \\
\hline Drug & Cross-Reactant \\
\hline Cannabinoids & NSAIDs, Marinol, Protonix \\
\hline Opioids & Poppy seeds, chlorpromazine, rifampin, dextromethorphan quinine \\
\hline Amphetamines & $\begin{array}{l}\text { Ephedrine, methylphenidate, trazodone, bupropion, desipramine, Amantadine, ranitidine, phenylpropanolamine, } \\
\text { Vicks Vapor Spray }\end{array}$ \\
\hline PCP & Chlorpromazine, thioridazine, meperidine, dextromethorphan, diphenhydramine, doxylamine \\
\hline Benzodiazepine & Oxaprozin (Daypro ${ }^{\circ}$ ), some herbal agents \\
\hline ETOH & Asthma inhalers (sometimes) \\
\hline Methadone & propoxyphene, Seroquel \\
\hline
\end{tabular}

Gas chromatography should confirm all positives and screen detects a presence of absence, not the concentration. Drug tests are not quantitative. Source: Manchikanti L, et al. Monitoring opioid adherence in chronic pain patients: Tools, techniques and utility. Pain Physician 2008; 11:S155S180 (22). 
Table 4 illustrates drug testing for cocaine, its specificity, pitfalls, and myths, Table 5 illustrates urine drug testing for marijuana, which is moderately specific, and
Table 6 illustrates drug testing for amphetamines with low specificity. Table 7 illustrates pitfalls of opioid drug testing, along with cross-reactivity.

Table 3. Metabolites of opioids.

\begin{tabular}{|c|c|c|}
\hline OPIATE & METABOLITES & COMMENT \\
\hline Hydrocodone & $\begin{array}{l}\text { Hydromorphone } \\
\text { Dihydrocodeine } \\
\text { Normorphine } \\
\text { Norhydrocodone } \\
\text { Hydrocodol } \\
\text { Hydromorphol } \\
\end{array}$ & $\begin{array}{l}\text { If codeine to hydrocodone ratio }<10 \text {, codeine is not the } \\
\text { sole source } \\
\text { Level generally lower than its hydrocodone source and } \\
\text { below detection if only codeine was ingested }\end{array}$ \\
\hline Oxycodone & $\begin{array}{l}\text { Oxymorphone } \\
\text { Noroxycodone } \\
\text { Oxycodols and their respective oxide }\end{array}$ & \\
\hline Morphine & $\begin{array}{l}\text { Hydromorphone (minor) } \\
\text { Morphine-3-glucuronide } \\
\text { Morphine-6-glucuronide } \\
\text { Normorphine }\end{array}$ & $\begin{array}{l}\text { If codeine to morphine ratio }<6 \text {, codeine is likely not the } \\
\text { sole source } \\
\text { Level generally lower than its hydrocodone source and } \\
\text { below detection if only codeine was ingested }\end{array}$ \\
\hline Methadone & $\begin{array}{l}\text { 2-Ethylidene-1, 5-dimethyl-3, 3-diphenylpyrrolidine } \\
\text { 2-Ethyl-5-methyl-3, 3-diphenylpyrrolidine }\end{array}$ & \\
\hline Hydromorphone & $\begin{array}{l}\text { Dihydromorphine } \\
\text { Hydromorphone-3-glucuronide }\end{array}$ & $\begin{array}{l}\text { Level generally lower than its hydrocodone source and } \\
\text { below detection if only codeine was ingested }\end{array}$ \\
\hline Oxymorphone & $\begin{array}{l}\text { Oxymorphone-3-gluucornide } \\
\text { Oxymorphol }\end{array}$ & \\
\hline Codeine & $\begin{array}{l}\text { Hydrocodone (minor) } \\
\text { Norcodeine } \\
\text { Morphine }\end{array}$ & $\begin{array}{l}\text { If codeine to hydrocodone ratio }<10 \text {, codeine is not the } \\
\text { sole source } \\
\text { If codeine to morphine ratio }<6 \text {, codeine is likely not the } \\
\text { sole source } \\
\text { Level generally lower than its hydrocodone source and } \\
\text { below detection if only codeine was ingested }\end{array}$ \\
\hline Propoxyphene & Norpropoxyphene & \\
\hline Fentanyl & Norfentanyl & \\
\hline Tramadol & $\begin{array}{l}\text { O-desmethyl-tramadol } \\
\text { Nortramadol }\end{array}$ & \\
\hline Butorphanol & $\begin{array}{l}\text { Hydroxybutorphanol } \\
\text { Norbutorphanol }\end{array}$ & \\
\hline Buprenorphine & $\begin{array}{l}\text { Norbuprenorphine } \\
\text { Norbuprenorphine-3-glucuronide } \\
\text { Buprenorphine-3-glucuronide }\end{array}$ & \\
\hline Heroin & $\begin{array}{l}\text { Morphine } \\
\text { Codeine (contaminant) } \\
\text { 6-Monoacetylmorphine }\end{array}$ & \\
\hline
\end{tabular}

Modified from: Manchikanti L, et al. Monitoring opioid adherence in chronic pain patients: Tools, techniques and utility. Pain Physician 2008; 11:S155-S180 (22); Oyler JM et al. Identification of hydrocodone in human urine following codeine administration. J Analytical Toxicology 2000; 24:530-535 (32); and Cone EJ, Caplan YH. Urine toxicology testing in chronic pain management. Postgrad Med 2009; 121:91-102 (23). 
Table 4. Urine drug testing methods for cocaine.

- Cocaine Testing: High Specificity

- Tests for cocaine react principally with cocaine and its primary metabolite, benzoylecgonine.

- These tests have low cross-reactivity with other substances.

- Very specific in predicting cocaine use.

- Cocaine, a topical anesthetic, is clinically used in certain trauma, dental, ophthalmoscopic, and otolaryngologic procedures.

- A patient's urine may test positive for up to 2 to 3 days.

- There is no structural similarity between other "caines" and cocaine or benzoylecgonine.

- Cross-reaction does not occur.

A positive UDT result for the cocaine metabolite, in the absence of a medical explanation, should be interpreted as due to deliberate use.

\section{- Cocaine Myths}

- Coca Tea

- There have been rare, but documented, cases of cocaine ingestion by drinking tea made from coca leaves.

- The product - containing cocaine and/or related metabolites-is illegal under the U.S. Drug Enforcement Administration and Food and Drug Administration regulations.

- Patients should be advised not to use coca tea.

Source: Manchikanti L, et al. Monitoring opioid adherence in chronic pain patients: Tools, techniques and utility. Pain Physician 2008; 11: S155-S180 (22).

Table 5. Urine drug testing for marijuana.

- THC: Marijuana: Moderate Specificity

- Reasonable reliability

- Positive result

- Marinol

- False-positive result

- Protonix

- Hemp products

\section{- Marijuana Myths}

- Passive Inhalation

- In extreme conditions (e.g., it is possible to blow enough smoke in an individual's face to cause them to become positive for marijuana).

- But, cannot occur without the patient's knowledge.

- Medical Marijuana

- $\mathrm{Marinol}^{\circ}$ for the control of nausea, vomiting, and appetite stimulating.

- More specific testing would be required to distinguish between natural and synthetic THC.

Source: Manchikanti L, et al. Monitoring opioid adherence in chronic pain patients: Tools, techniques and utility. Pain Physician 2008; 11:S155-S180 (22).

\subsection{Clinical Significance}

Urine drug screening testing has become the standard of care for patients on controlled substances. However, the relative value of in-office screening and laboratory confirmation of those tests is sometimes unclear or controversial for physicians. The POC manufacturers recommend that their tests need to be confirmed. However, advantages and cost benefits have
Table 6. Drug testing for amphetamines.

\section{- Low Specificity}

- Tests for amphetamine/methamphetamine are highly cross-reactive.

- They will detect other sympathomimetic amines such as ephedrine and pseudoephedrine.

- Not very predictive for amphetamine/methamphetamine use.

- Further testing is required.

- Positive results can be challenging due to structural similarities of:

- Many prescription and OTC products, including diet agents, decongestants, and certain drugs used in the treatment of Parkinson's disease.

- Knowledge of potential sources of amphetamine and methamphetamine can prevent misinterpretation of results.

Source: Manchikanti L, et al. Monitoring opioid adherence in chronic pain patients: Tools, techniques and utility. Pain Physician 2008; 11:S155-S180 (22).

not been evaluated and confirmed independently. Multiple manufacturers are lobbying for laboratory confirmation for each and every test performed, increasing the cost exponentially.

\subsection{Millennium Laboratories}

The preliminary data from Millennium Laboratories on 4,200 blindly sampled urine drug screens from a diverse population of chronic pain patients supports manufacturers' view (34):

The urine samples were tested by immunoassay and LC/MS/MS for amphetamine class, benzodiazepine 
Table 7. Pitfalls of opioid drug testing.

- Pitfalls

- Tests for opiates are very responsive for morphine and Codeine.

- Do not distinguish which is present.

- Show a low sensitivity for semisynthetic/synthetic opioids such as oxycodone.

- A negative response does not exclude oxycodone, methadone use.

- Opiate immunoassays designed to detect morphine and codeine do not reliably detect synthetic or semisynthetic opioids.

- Cross-reacting compounds can also be structurally unrelated to the standardizing compound.

- Several quinolone antibiotics (e.g., levofloxacin, ofloxacin) can potentially cause false-positive results for opiates by common immunoassays, despite no obvious structural similarity with morphine.

- Quinolones are not misinterpreted as opiates by GC/MS.

- Cross-reactivity

- Detection of a particular drug by a drug-class specific immunoassay depends on:

- The structural similarity of that drug or its metabolites to the compound used for standardization.

- The urine concentration of that drug/metabolite, compared with the standardizing compound.

- The ability of opiate immunoassays to detect synthetic or semisynthetic opioids, such as methadone or oxycodone, varies among assays due to differing cross-reactivity patterns.

- Methadone, although an opioid, does not trigger a positive opioid immunoassay result unless a specific methadone test is used.

- In the case of oxycodone, even large concentrations in the urine may not reliably be detected.

Source: Manchikanti L, et al. Monitoring opioid adherence in chronic pain patients: Tools, techniques and utility. Pain Physician 2008; 11: S155-S180 (22).

class, cannabinoids, cocaine, opiates class, and propoxyphene class.

In a number of patients, immunoassay findings, falsely thought to be negative, were determined to be positive by the mass spectroscopy analysis. The greatest detection failures (false-negatives) were for the benzodiazepine class (28\%). The increased sensitivity of LC/ MS/MS doubles the number of cocaine-positive urine (from $2.2 \%$ to $4.5 \%$ ). The new Federal NLCP testing guidelines have recognized that the current $300 \mathrm{ng} / \mathrm{mL}$ cutoff for the cocaine metabolite is too high. At this level, tests show many false-negative observations. As a result, the screening cutoff has been lowered from $300 \mathrm{ng} / \mathrm{mL}$ to $150 \mathrm{ng} / \mathrm{mL}$. At present, such POC testing kits are not available.

\subsection{AIT Laboratories}

Evans et al (35) published a manuscript on effective monitoring of opiates in chronic pain patients. They evaluated 111,872 urine specimens collected over a one-year time period from pain treatment facilities throughout the U.S. They were evaluated in order to quantify the number of specimens that may have tested negative according to traditional urine drug testing devices but tested positive in the laboratory where lower cut-off levels were utilized. Of the 77,881 specimens that screened positive for opiates at levels of $50 \mathrm{ng} / \mathrm{mL}$ or higher in the laboratory, $59.05 \%$ fell below typical POC device cut-off level of $2,000 \mathrm{ng} / \mathrm{mL}$.
Further, they reported that $23.34 \%$ fell below $300 \mathrm{ng} /$ $\mathrm{mL}$, the typical cut-off level used by clinical, hospital, and reference laboratories. They concluded that this suggests that of those patients who were prescribed opiates, a substantial proportion of positive specimens may have gone undetected unless specimens were submitted to a laboratory using a low cut-off level for initial screening.

\subsection{Ameritox}

Couto et al (36) evaluated high rates of inappropriate drug use in the chronic pain population. Their objective was to study rates of inappropriate utilization, abuse, and diversion in a population of patients who were prescribed chronic opioids, as measured by urine drug testing in the clinical setting. They conducted a retrospective analysis with the results from all urine drug testing conducted by Ameritox, Ltd., between January 2006 and January 2009 for patients whose physicians ordered the test in order to screen for non-compliance. They collected data from 938,586 patient test samples and showed that $75 \%$ of the patients were unlikely to be taking their medications in a manner consistent with their prescribed pain regimen. Thirty-eight percent of patients were found to have no detectable level of their prescribed medication, $29 \%$ had a nonprescribed medication present, $27 \%$ had a drug level higher than expected, $15 \%$ had a drug level lower than expected, and $11 \%$ had illicit drugs detected in their urine. 


\subsection{Dominion Laboratories}

Dominion Laboratories, a manufacturer of POCs, and provider of laboratory testing (37), alleges that CLIA POC testing is creating a financial incentive for physicians and they recommend physicians and physicians' offices should send all samples to the laboratory for confirmation.

However, these allegations are based on creative accounting and financial bias.

\subsection{Unreliability of Results}

While all the companies claim a specific type of evaluation system, each one is associated with their own biases, different types of cut-off levels in data presentation, and exaggeration. Thus, these results may not be reliable or generalizable.

Even then, their reported prevalence of drug abuse and illicit drug use was not that significantly different from the reported data in clinical settings when it was performed appropriately utilizing the general population receiving opioids in pain management settings.

\subsection{Assessment of Diagnostic Accuracy STUDIES}

The world of diagnostic tests is highly dynamic. New tests are developed at a fast rate and the technology of existing tests is continuously being improved (38). Exaggerated and biased results from poorly designed and reported diagnostic studies can trigger their premature dissemination and lead physicians into making incorrect treatment decisions. Since the diagnosis is a critical component of health care, clinicians, policy makers, and patients routinely face a range of questions regarding diagnostic tests (39). Well-designed diagnostic test accuracy studies can help in making appropriate diagnosis, improving outcomes, and in designing practice guidelines $(40,41)$.

\subsection{Definition of Diagnostic Accuracy}

In studies of diagnostic accuracy, the outcomes from one or more tests under evaluation are compared with outcomes from the reference standard, both measured in subjects who are suspected of having the condition of interest. The term "test" refers to any method of obtaining additional information on a patient's health status. It includes information from history and physical examination, laboratory tests, imaging tests, function tests, and histopathology. In this framework, the reference standard is considered to be the best available method for establishing the presence or absence of the condition of interest. For urine drug testing the reference standard can be a single method - laboratory testing with LC/MS/MS.

\subsection{STARD Initiative}

The Standards for Reporting of Diagnostic Accuracy (STARD) established reporting guidelines for diagnostic accuracy studies to improve the quality of reporting (38). They developed a checklist for the reporting of studies of diagnostic accuracy which included 25 items in 5 sections: title/abstract/key words, introduction, methods, results, and discussion. They also have provided a prototypical flow diagram of a diagnostic accuracy study (38).

\subsection{Bias and Variation in Studies of Diagnos- tic Accuracy}

In a classic diagnostic accuracy study, a consecutive series of patients who are suspected of having the target condition, undergo the index test, then all patients are verified by the same reference standard. The index test and reference standard are then read by persons blinded to the results of each and various measures of agreement are calculated including sensitivity, specificity, likelihood ratios, and diagnostic odds ratios. The classic design has many variations, including differences in the way patients are selected for the study, in test protocol, in the verification of patients, and in the way the index test and reference standard are read. Some of the differences may bias the results of a study and others may limit the applicability of results (42).

Variations arise from the differences among studies in terms of population, setting, test protocol, or definition of the target disorder (43). The variability does not lead to biased estimates of the test performance; rather, it limits the applicability of results.

While bias and variation are different, the distinctions are not (44). The design features associated with significant overestimations of diagnostic accuracy are inclusion of severe cases and healthy controls, non-consecutive inclusion of patients, and retrospective data collection.

In urine drug testing in interventional pain management bias and variations may be introduced when the testing is performed only on select patients with suspicion or for certain reasons and also by sending some of the samples to the laboratory for confirmation. Randomized or sequential study of patients with blinding of assessment will provide appropriate validity. 


\subsection{Quality Assessment}

Several instruments have been designed for methodologic quality assessment of diagnostic studies. West et al (45), in the Agency for Healthcare Research and Quality (AHRQ) evidence report of technology assessment, provided pertinent evidence for rating the quality of individual articles including the studies of diagnostic tests. AHRQ developed 5 key domains for making judgments about the quality of diagnostic test reports: study population, adequate description of the test, appropriate reference standard, blinded comparison of test and reference, and avoidance of verification bias.

\subsection{Objectives}

\subsection{Primary Objective}

The primary objective of this study is to compare the information obtained by POC in-office testing (index test) to the information found when all drugs and analytes are tested by LC/MS/MS (reference test) in the same urine sample.

\subsubsection{Secondary Objectives}

Secondary objectives are related to correlation of clinical factors in relation to threshold levels, prevalence of abuse, false-positives, false-negatives, influence of other drugs, and demographic characteristics.

\subsection{Proposed Hypothesis}

It is proposed that there is no significant different between POC drug testing (index test) and laboratory drug testing (reference test) of clinical importance. Thus, it is the objective of this study to prove the null hypothesis.

\subsubsection{Primary Endpoint}

To confirm null hypothesis with no significant differences in all the patients undergoing urine drug testing in the office (POC testing) compared to the reference gold standard (i.e. laboratory testing with LC/MS/MS).

\subsubsection{Secondary Endpoints}

Secondary outcome measures are related to correlation of clinical factors in relation to threshold levels, prevalence of abuse, false-positives, false-negatives, influence of other drugs, and demographic characteristics.

\subsection{Investigational Methodology}

The investigational methodology is designed based on the STARD checklist for the recommendations of studies of diagnostic accuracy.
All patients will be tested with POC drug testing (index test). All the specimens without identifying information, demographic, or clinical information will be sent to Millennium Laboratories for reference test.

\subsection{Participants}

\subsubsection{Study Population}

The study population is recruited from the Pain Management Center of Paducah and the Ambulatory Surgery Center, Paducah, Kentucky.

\subsubsection{Setting and Location}

The Pain Management Center and Ambulatory Surgery Center, Paducah, Kentucky, are interventional pain management practices and referral centers.

\subsubsection{Inclusion and Exclusion Criteria:}

- Inclusion criteria for urine drug testing include the following:

- Chronic pain management with or without controlled substance therapy.

- Exclusion criteria for urine drug testing include the following:

- None.

\subsubsection{Participant Recruitment}

The recruitment is based on the indications for urine drug testing which include:

- Chronic pain management with or without controlled substance therapy.

\subsubsection{Participants Sampling}

The study population is a consecutive series of participants defined by the selection criteria as described above.

\subsubsection{Data Collection}

The data collection is prospective.

\subsection{Test Methods}

\subsubsection{The Reference Standard and Its Rationale}

The index test is the in-house office drug testing or POC testing.

The reference standard can be a single method — laboratory testing with LC/MS/MS.

The rationale is that the laboratory test will be performed by a laboratory which meets CLIA requirements regarding QA, QC, and proficiency testing. This labora- 
tory holds certificates for moderate or high complexity testing and the requirements are much more stringent than a CLIA waived testing such as the index test. In addition, the laboratory tests must be performed by individuals with a specific level of education and training.

\subsubsection{Screening Evaluation}

A patient considered suitable for participation in the urine drug assessment diagnostic accuracy study will be given a verbal explanation of the study and adherence monitoring. All of the patients have already signed informed consent for drug testing and adherence monitoring. If such an informed consent is not available, a new informed consent will be obtained. The principal investigator or member of the investigative team will address any questions regarding the investigation appropriately.

Each subject considered for entry into the investigation will have the following information procedures done during the screening period:

- Demographic details including date of birth, sex, weight, height

- Drug profile

- List of all prescription, over the counter, and all other drugs or substances

\subsubsection{Treatment Number Assignment}

Subjects will be consequently assigned with a number. Once the patient is included in the study, the same number will remain.

\subsubsection{Urine Sample}

Urine will be collected by one of the nurses. POC testing will be performed by a different nurse who is unaware of the patient's name, drug intake, etc. Urine and all the appropriate information will be collected by a nurse participating in the study and provided to the study coordinator.

Drug testing is performed for following drugs:

- Opioids

- Hydrocodone

- Oxycodone

- Methadone

- Morphine

- Morphine-3-glucuronide

- Codeine

- Hydromorphone

- Oxymorphone

- Heroin

- Benzodiazepines
- Diazepam

- Alprazolam

- Clonazepam

- Oxazepam

- Chlordiazepoxide

- Lorazepam

- Nordazepam

- Prazepam

- Temazepam

- Barbiturates (immunoassay only)

- Secobarbital

- Allobarbital

- Alphenal

- Amobarbital

- Aprobarbital

- Barbital

- Butabarbital

- Butalbital

- Butethal

- Pentobarbital

- Phenobarbital

- Carisoprodol (Soma)

- Other Drugs

(Darvocet)

- Propoxyphene Napsylate and Acetaminophen

- Tramadol $\mathrm{HCl}$ (Ultram)

- Cocaine

- Marijuana

- PCP

- Cannabinol

- Amphetamines

- Methamphetamine

- Tricyclic Antidepressants (immunoassay only)

- Nortriptyline

- Nordoxepin

- Trimipramine

- Amitriptyline

- Promazine

- Desipramine

- Doxepin

- Maprotiline

\subsubsection{Laboratory Assessment}

The sample will be sent to Millennium Laboratories. Millennium Laboratories will perform the test using LC/MS/MS methodology.

Millenium will forward the test results to Ambulatory Surgery Center, 2831 Lone Oak Road, Paducah, Kentucky 42003, by secured fax, e-mail, or mail. 


\subsubsection{Definition and Rationale}

The definition and rationale for the units, cut-offs, and categories of the results of the index test and the reference standard are derived by federally regulated and non-regulated testing, clinical implications, and literature review. These are determined to be at the safest and most appropriate levels for the clinician in managing substance use and abuse.

\subsubsection{Personnel}

The number, training, and expertise of the persons reading the index test and the reference standard includes conducting and reading the index test and the reference standard.

All personnel have been trained to perform the POC testing. Similarly, all personnel hold appropriate certifications to perform the reference test.

\subsubsection{Blinding}

The personnel performing and reading the index test and reference will be blinded (masked) to the results of other tests and patient demographics, as well as any other clinical information available to data synthesis personnel.

\subsection{Statistical Methods}

\subsubsection{Sample Size}

Sample size calculation was carried out for our primary outcome (accuracy of the POC drug testing in screening for medicines such as opiates, benzodiazepines, illicit drugs, and other related medicines) according to the previously published method by Jones et al (46). This method is used to calculate the sample size required to estimate an expected level of sensitivity with a predefined degree of precision (CI) (46). According to previous results of drug abuse and illicit drug use of patients referred to clinics we estimated a prevalence of drug abuse (misuse) as $9 \%$ and illicit drug use as $16 \%$ among our study population (10). Using the prevalence of $9 \%$ drug abuse and an expected level of sensitivity of $95 \%$, with a $\mathrm{Cl}$ of $5 \%$, we calculated a required study sample size of 811 . To compensate for missing data and for patients with incomplete data (= patients with incomplete reference standard test results) that will have to be excluded, we plan to enroll 1,000 patients in our study. Considering the current number of patients that are visiting our outpatient clinic for the management of pain and considering the feasibility to perform the urine drug tests and the other interventional procedures at our clinic we plan to recruit 1,000 patients within 6 months.

\subsubsection{Statistical Analyses}

Statistical analyses will be performed by the SPSS 11.0 statistical package (SPSS, Inc., Chicago IL, USA). A $P$ value below 0.05 will be considered statistically significant.

Results of POC drug testing (index test) will be compared to laboratory drug testing (reference test) in all patients. The sensitivity, specificity, PPV, NPV, and accuracy will be calculated including $95 \% \mathrm{Cls}$.

\subsubsection{Definitions of the Operative Features of Diag- nostic Tests}

Sensitivity: Probability that a test result will be positive when the disease (drug) is present (true-positive rate).

Specificity: Probability that a test result will be negative when the disease (drug) is not present (truenegative rate).

Negative likelihood ratio: Ratio between the probability of a negative test result given the presence of the disease (drug) and the probability of a negative test given the absence of the disease (drug).

Positive predictive value: Probability that the disease (drug) is present when the test is positive.

Negative predictive value: Probability that the disease is not present when the test is negative.

\subsection{Results}

\subsubsection{Flow Diagram}

The STARD flow diagram is utilized.

\subsubsection{Participants}

The start date of the study is February 1, 2010, and ending date is expected as June 30, 2010.

\subsubsection{Demographic Characteristics}

The demographic characteristics of the study population will be described.

\subsubsection{Numbers Analyzed}

The numbers from satisfying the criteria for inclusion that did or did not undergo the index test and/or the reference standard will be described along with the reasons why they failed to receive either test. This is illustrated in the flow diagram. 


\subsubsection{Time Intervals}

Time interval from the index test to the reference standard will be described. This is estimated not to exceed 72 hours. Millennium Laboratory's procedure is to refrigerate the samples in their container for 2 weeks before disposal. An aliquot is stored for one month before disposal. They can freeze this aliquot at $-20^{\circ}$ celsius for as long as necessary.

\subsubsection{Distribution Characteristics}

Distribution of severity of disease is not defined and it not relevant to the present evaluation.

\subsubsection{Cross Tabulation of the Results}

A cross tabulation of the results of the index testing including indeterminate and missing results by the results of the reference standard will be performed for continuous results, the distribution of the test results, by the results of the reference standard.

\subsubsection{Adverse Events}

Any adverse events while performing the index test will be reported; however, no adverse events are expected in this evaluation.

\subsubsection{Estimates}

The study will estimate:

- $95 \%$ confidence intervals.

- Description of how indeterminate results, missing responses, and outliers of the index test were handled.

- Estimates of variability of diagnostic accuracy between compliant and non-compliant patients, appropriate drug users, and abusers.

\subsubsection{Estimations of Test Reproducibilities}

Ten percent of the samples can be split given a separate ID and submitted for analysis. The results of the split specimens can be compared. This should establish the test reproducibility.

\subsection{Conclusion}

This article describes the protocol for accuracy of POC in-office urine drug testing immunoassay in chronic pain patients in a prospective analysis of immunoassay and LC/MS/MS. In an interventional pain management center and a referral center in the United States, the protocol utilizes approved methodology with STARD initiative, appropriate consent, and the Health Insurance Portability and Accountability Act (HIPAA) and ethical regulations, this study is the first of its nature in the United States in urine drug testing for adherence monitoring of chronic pain patients receiving controlled substances.

\section{Acknowledgments}

The authors wish to thank Tonie M. Hatton and Diane E. Neihoff, transcriptionists, and Lorie A. Caldwell, medical records coordinator; for their assistance in preparation of this manuscript. The authors would also like to thank the editorial board of Pain Physician for their constructive comments.

\section{Author affiliation}

Dr. Manchikanti is Medical Director of the Pain Management Center of Paducah, Paducah, KY, and Associate Clinical Professor, Anesthesiology and Perioperative Medicine, University of Louisville, Louisville, KY. Dr. Malla is an Interventional Pain Physician at the Pain Management Center of Paducah, Paducah, KY. Dr. Wargo is an Interventional Pain Physician at the Pain Management Center of Paducah, Paducah, KY. Mrs. Cash is a Research Coordinator at the Pain Management Center of Paducah, Paducah, KY. Mr. Pampati is a Statistician at the Pain Management Center of Paducah, Paducah, KY. Mrs. Damron is a Nursing Administrator at the Pain Management Center of Paducah, Paducah, KY. Mrs. McManus is a Nursing Administrator at the Pain Management Center of Paducah, Paducah, KY. Ms. Brandon is a Surgical Technologist at the Pain Management Center of Paducah, Paducah, KY.

\section{References}

1. Manchikanti L, Singh A. Therapeutic opioids: A ten year perspective on the complexities and complications of the escalating use, abuse, and non-medical use of opioids and other psychotherapeutics. Pain Physician 2008; 11: S63-S88.
2. Manchikanti L. National drug control policy and prescription drug abuse: Facts and fallacies. Pain Physician 2007; 10:399-424.

3. Manchikanti L. Prescription drug abuse: What is being done to address this new drug epidemic? Testimony be- fore the Subcommittee on Criminal Justice, Drug Policy and Human Resources. Pain Physician 2006; 9:287-321.

4. Manchikanti L, Whitfield E, Pallone F. Evolution of the National All Schedules Prescription Electronic Reporting Act 
(NASPER): A public law for balancing treatment of pain and drug abuse and diversion. Pain Physician 2005; 8:335347.

5. Trescot AM, Helm S, Hansen H, Benyamin R, Glaser SE, Adlaka R, Patel S, Manchikanti L. Opioids in the management of chronic non-cancer pain: An update of American Society of the In terventional Pain Physicians' (ASIPP) guidelines. Pain Physician 2008; 11:S5S62.

6. Bollinger LC, Bush C, Califano JA, Chenault KI, Curtis JL, Dimon J, Dolan PR, Ganzi VF, Fisher M, Kelmenson LA, Keough DR, Kessler DA, Malloy EA, Pacheco MT, Plumeri II JJ, Redstone SE, Rosenwald Jr EJ, Schulhof MP, Sullivan LW, Sweeney JJ, Wiener MA. Under the counter. The diversion and abuse of controlled prescription drugs in the U.S. The National Center on Addition and Substance Abuse at Columbia University (CASA), July 2005.

7. Substance Abuse and Mental Health Services Administration. (2007). Results from the 2006 National Survey on Drug Use and Health: National Findings. (Office of Applied Studies, NSDUH Series H-32, DHHS Publication No. SMA 07-4293). Rockville, MD. www.oas.samhsa.gov

8. Zacny J, Bigelow G, Compton P, Foley K, Iguchi M, Sannerud C. College on Problems of Drug Dependence task force on prescription opioid non-medical use and abuse: Position statement. Drug Alcohol Depend 2003; 69:215-232.

9. Manchikanti L, Giordano J, Boswell MV, Fellows B, Manchukonda R, Pampati V. Psychological factors as predictors of opioid abuse and illicit drug use in chronic pain patients. J Opioid Manage 2007; 3:89-100.

10. Manchikanti L, Cash KA, Damron KS, Manchukonda R, Pampati V, McManus CD. Controlled substance abuse and illicit drug use in chronic pain patients: An evaluation of multiple variables. Pain Physician 2006; 9:215-226.

11. Manchikanti L, Manchukonda R, Damron KS, Brandon D, McManus CD, Cash $K A$. Does adherence monitoring reduce controlled substance abuse in chronic pain patients? Pain Physician 2006; 9:57-60.

12. Manchikanti L, Manchukonda R, Pampati V, Damron KS. Evaluation of abuse of prescription and illicit drugs in chronic pain patients receiving short-acting (hydrocodone) or long-acting (methadone) opioids. Pain Physician 2005; 8:257-261.

13. QuickStats: Motor-Vehicle Traffic* and Poisoning† Death Rates§, by Age --. United States, 2005-2006. Morbidity and Mortality Weekly Report (MMWR). July 17, 2009; 58:753.

14. Manchikanti L, Damron KS, McManus CD, Barnhill RC. Patterns of illicit drug use and opioid abuse in patients with chronic pain at initial evaluation: A prospective, observational study. Pain Physician 2004; 7:431-437.

15. Manchikanti L, Damron KS, Pampati V, McManus CD, Weaver SE. Prospective evaluation of patients with increasing opiate needs: Prescription opiate abuse and illicit drug use. Pain Physician 2004; 7:339-344.

16. Chelminski PR, Ives TJ, Felix KM, Prakken SD, Miller TM, Perhac JS, Malone RM, Bryant ME, DeWalt DA, Pignone MP. A primary care, multi-disciplinary disease management program for opioid-treated patients with chronic noncancer pain and a high burden of psychiatric comorbidity. BMC Health Serv Res 2005; 5:3.

17. Katz NP, Sherburne S, Beach M, Rose RJ, Vielguth J, Bradley J, Fanciullo GJ. Behavioral monitoring and urine toxicology testing in patients receiving long-term opioid therapy. Anesth Analg 2003; 97:1097-1102.

18. Katz NP, Adams EH, Benneyan JC, Birnbaum HG, Budman SH, Buzzeo RW, Carr DB, Cicero TJ, Gourlay D, Inciardi JA, Joranson DE, Kesslick J, Lande SD. Foundations of opioid risk management. Clin J Pain 2007; 23:103-118.

19. Caplan YH, Goldberger BA. Alternative specimens for workplace drug testing. J Anal Toxicol 2001; 25:396-399.

20. Gourlay DL, Caplan YH, Heit HA. Urine Drug Testing in Clinical Practice: Dispelling the Myths and Designing Strategies, Edition 3. 2006.

21. Hammett-Stabler CA, Pesce AJ, Cannon DJ. Urine drug screening in the medical setting. Clin Chim Acta 2002; 315:125135 .

22. Manchikanti L, Atluri S, Trescot AM, Giordano J. Monitoring opioid adherence in chronic pain patients: Tools, techniques, and utility. Pain Physician 2008; 11:S155-S180.

23. Cone EJ, Caplan YH. Urine toxicology testing in chronic pain management. Postgrad Med 2009; 121:91-102.
24. Melanson SE, Kredlow MI, Jarolim P. Analysis and interpretation of drug testing results from patients on chronic pain therapy: A clinical laboratory perspective. Clin Chem Lab Med 2009; 47:971-976.

25. Nafziger AN, Bertino JS Jr. Utility and application of urine drug testing in chronic pain management with opioids. Clin J Pain 2009; 25:73-79.

26. Wasan AD, Michna E, Janfaza D, Greenfield S, Teter CJ, Jamison RN. Interpreting urine drug tests: Prevalence of morphine metabolism to hydromorphone in chronic pain patients treated with morphine. Pain Med 2008; 9:918-923.

27. Gianutsos LP, Safranek S, Huber T. Clinical inquiries: Is there a well-tested tool to detect drug-seeking behaviors in chronic pain patients? J Fam Pract 2008; 57:609-610.

28 Tellioglu T. The use of urine drug testing to monitor patients receiving chronic opioid therapy for persistent pain conditions. Med Health R / 2008; 91:279280, 282.

29. Code of Federal Regulations. 49 CFR §40. Office of the Federal Register. 1998. www.access.gpo.gov/nara/cfr/ cfr-table-search.html

30. Simpson D, Braithwaite RA, Jarvie DR, Stewart MJ, Walker S, Watson IW, Widdop B. Screening for drugs of abuse (II): Cannabinoids, lysergic acid diethylamide, buprenorphine, methadone, barbiturates, benzodiazepines and other drugs. Ann Clin Biochem 1997; 34:460-510.

31. Office of National Drug Control Policy. What You Need to Know About Drug Testing in Schools. 2002. www.whitehousedrugpolicy.gov/pdf/drug_testing.pdf

32. Oyler JM, Cone EJ, Joseph RE Jr, Huestis MA. Identification of hydrocodone in human urine following codeine administration. J Analytical Toxicology 2000; 24:530-535.

33. Cone EJ. New developments in biological measures of drug prevalence. NIDA Res Monogr 1997; 167:108-129.

34. Personal Correspondence. Millennium Laboratories, August 2009.

35. Evans M, Kriger S, Gunn J, Schwilke G. Effective monitoring of opiates in chronic pain patients. Pract Pain Manag 2009; 9:32-33.

36. Couto JE, Romney MC, Leider HL, Sharma S, Goldfarb NI. High rates of inap- 
propriate drug use in the chronic pain population. Popul Health Manage 2009; 12:185-190.

37. Dominion Diagnostics. Medication Monitoring. Presented to National Council of Self-Insurers. May 18, 2009.

38. Bossuyt PM, Reitsma JB, Bruns DE, Gatsonis CA, Glasziou PP, Irwig LM, Lijmer JG, Moher D, Rennie D, de Vet HC; Standards for Reporting of Diagnostic Accuracy. Towards complete and accurate reporting of studies of diagnostic accuracy: The STARD initiative. Clin Chem 2003; 49:1-6.

39. Leeflang MM, Deeks JJ, Gatsonis C, Bossuyt PM; Cochrane Diagnostic Test Accuracy Working Group. Systematic reviews of diagnostic test accuracy. Ann Intern Med 2008; 149:889-897.

40. Manchikanti L, Derby R, Wolfer L, Singh V, Datta S, Hirsch JA. Evidence-based medicine, systematic reviews, and guidelines in interventional pain management: Part 5. Diagnostic accuracy studies. Pain Physician 2009; 12:517540.

41. Manchikanti L, Derby R, Wolfer L, Singh V, Datta S, Hirsch JA. Evidence-based medicine, systematic reviews, and guidelines in interventional pain management: Part 7: Systematic reviews and meta-analyses of diagnostic accuracy studies. Pain Physician 2009; 12:929-963.

42. Whiting P, Rutjes AW, Reitsma JB, Glas AS, Bossuyt PM, Kleijnen J. Sources of variation and bias in studies of diag nostic accuracy: A systematic review. Ann Intern Med 2004; 140:189-202.

43. Bossuyt PM, Reitsma JB, Bruns DE, Gatsonis CA, Glasziou PP, Irwig LM, Moher D, Rennie D, de Vet HC, Lijmer JG; Standards for Reporting of Diagnostic Accuracy. The STARD statement for report- ing studies of diagnostic accuracy: Explanation and elaboration. Clin Chem 2003; 49:7-18.

44. Rutjes AW, Reitsma JB, Di Nisio M, Smidt N, van Rijn JC, Bossuyt PM. Evidence of bias and variation in diagnostic accuracy studies. CMAJ 2006; 174:469-476.

45. West S, King V, Carey TS, Lohr KN, McKoy N, Sutton SF, Lux L. Systems to Rate the Strength of Scientific Evidence, Evidence Report, Technology Assessment No. 47. AHRQ Publication No. 02E016. Rockville, MD: Agency for Healthcare Research and Quality, 2002. www. thecre.com/pdf/ahrq-system-strength. pdf

46. Jones SR, Carley S, Harrison M. An introduction to power and sample size estimation. Emerg Med J 2003; 20:453458. 


\title{
APPENDIX I \\ ACCURACY OF POINT OF CARE (POC) OR IN-OFFICE URINE DRUG TESTING (IMMUNOASSAY) IN CHRONIC PAIN PATIENTS: A PROSPECTIVE ANALYSIS OF IMMUNOASSAY AND LIQUID CHROMATOGRAPHY TANDEM MASS SPECTOMETRY (LC/MS/MS)
}

\author{
PAIN MANAGEMENT CENTER OF PADUCAH
}

\section{CONTROLLED SUBSTANCE AGREEMENT}

We at the Pain Management Center of Paducah are committed to doing all we can to treat your chronic pain condition. In some cases, controlled substances are used as a therapeutic option in the management of chronic pain and related anxiety and depression, which is strictly regulated by both state and federal agencies. This agreement is a tool to protect you, the Pain Management Center of Paducah, and your physician by establishing guidelines, within the laws, for proper controlled substance use. The words "we" and "our" refer to the Pain Management Center of Paducah, and the words "I," "you," "your," "me," or "my" refer to you, the patient.

1. i. I understand that chronic opioid therapy has been associated with not only addiction and abuse, but also multiple medical problems including the suppression of endocrine function resulting in low hormonal levels in men and women which may affect mood, stamina, sexual desire, and physical and sexual performance.

ii. For female patients: If I plan to become pregnant or believe that I have become pregnant while taking this medication, I am aware that, should I carry the baby to delivery while taking these medications; the baby will be physically dependent upon opioids. I will immediately call my obstetrician and this office to inform them of my pregnancy. I am also aware that opioids may cause a birth defect, even though it is extremely rare.

iii. I have been informed that long-term and/or high doses of pain medications may also cause increased levels of pain known as opioid induced hyperalgesia (pain medicine causing more pain) where simple touch will be predicted as pain and pain gradually increases in intensity and also the location with hurting all over the body. I understand that opioid-induced hyperalgesia is a normal, expected result of using these medicines for a long period of time. This is only treated with addition of non-steroidal anti-inflammatory drugs such as Advil, Ibuprofen, etc., or by reducing or stopping opioids.

iv. I understand that physical dependence is not the same as addiction. I am aware physical dependence means that if my pain medicine use is markedly decreased, stopped, or reversed by some of the agents mentioned above, I will experience a withdrawal syndrome. This means I may have any or all of the following: runny nose, yawning, large pupils, goose bumps, abdominal pain and cramping, diarrhea, irritability, aches throughout my body, and a flu-like feeling. I am aware that opioid withdrawal is uncomfortable, but not life threatening.

v. I am aware that tolerance to analgesia means that I may require more medicine to get the same amount of pain relief. I am aware that tolerance to analgesia does not seem to be a big problem for most patients with chronic pain; however, it has been seen and may occur to me. If it occurs, increasing doses may not always help and may cause unacceptable side effects. Tolerance or failure to respond well to opioids may cause my doctor to choose another form of treatment, reduce the dose, or stop it. 
Accuracy of Point of Care (Poc) or In-Office Urine Drug Testing (Immunoassay) in Chronic Pain Patients

\section{APPENDIX I - continued}

2. i. All controlled substances must come from the physician whose signature appears below or during his/her absence, by the covering physician, unless specific authorization is obtained for an exception.

ii. I understand that I must tell the physician whose signature appears below or during his/her absence, the covering physician, all drugs that I am taking, have purchased, or have obtained, even over-the-counter medications. Failure to do so may result in drug interactions or overdoses that could result in harm to me, including death.

iii. I will not seek prescriptions for controlled substances from any other physician, health care provider, or dentist. I understand it is unlawful to be prescribed the same controlled medication by more than one physician at a time without each physician's knowledge.

iv. I also understand that it is unlawful to obtain or to attempt to obtain a prescription for a controlled substance by knowingly misrepresenting facts to a physician or his/her staff or knowingly withholding facts from a physician or his/her staff (including failure to inform the physician or his/her staff of all controlled substances that I have been prescribed).

3. All controlled substances must be obtained at the same pharmacy where possible. Should the need arise to change pharmacies, our office must be informed. The pharmacy that you have selected is: Phone:

4. i. You may not share, sell, or otherwise permit others, including your spouse or family members, to have access to any controlled substances that you have been prescribed.

ii. Early refills will not be given. Renewals are based upon keeping scheduled appointments. Please do not make excessive phone calls for prescriptions or early refills and do not phone for refills after hours or on weekends.

iii. Medication changes will not be made between appointments unless medically necessary, which will be determined by the physician.

5. Unannounced pill counts, random urine or serum, or planned drug screening may be requested from you and your cooperation is required. Presence of unauthorized substances in urine or serum toxicology screens may result in your discharge from treatment by the Pain Management Center of Paducah and its physicians and staff.

6. I will not consume excessive amounts of alcohol in conjunction with controlled substances. I will not use, purchase, or otherwise obtain any other legal drugs except as specifically authorized by the physician whose signature appears below or during his/her absence, by the covering physician, as set forth in Section 1 above. I will not use, purchase, or otherwise obtain any illegal drugs, including marijuana, cocaine, etc. I understand that driving while under the influence of any substance, including a prescribed controlled substance or any combination of substances (e.g., alcohol and prescription drugs), which impairs my driving ability, may result in DUI charges.

7. Medications or written prescriptions may not be replaced if they are lost, stolen, get wet, are destroyed, left on an airplane, etc. If your medication has been stolen, it will not be replaced unless explicit proof is provided with direct evidence from authorities. A report narrating what you told the authorities is not enough. 


\section{APPENDIX I - continued}

8. In the event you are arrested or incarcerated related to legal or illegal drugs (including alcohol), refills on controlled substances will not be given.

9. I understand that failure to adhere to these policies may result in cessation of therapy with controlled substances prescribed by this physician and other physicians at the Pain Management Center of Paducah and that law enforcement officials may be contacted.

10. Ialso understand that the prescribing physician has permission to discuss all diagnostic and treatment details, including medications, with dispensing pharmacists, other professionals who provide your health care, or appropriate drug and law enforcement agencies for the purpose of maintaining accountability.

11. I affirm that I have full right and power to sign and to be bound by this agreement, that I have read it, and understand and accept all of its terms. A copy of this document has been given to me.

Patient's full name

Patient's signature

Date

Physician's signature

Date 


\title{
APPENDIX II \\ ACCURACY OF POINT OF CARE (POC) OR IN-OFFICE URINE DRUG TESTING (IMMUNOASSAY) IN CHRONIC PAIN PATIENTS: A PROSPECTIVE ANALYSIS OF IMMUNOASSAY AND LIQUID CHROMATOGRAPHY TANDEM MASS SPECTOMETRY (LC/MS/MS)
}

\author{
ADDENDUM TO CONSENT TO URINE SPECIMEN FOR URINE DRUG TESTING
}

You have previously consented to giving a urine specimen as part of your medical treatment with controlled medications.

Pain Management Center of Paducah, in addition to education, often participates in research projects designed to further our understanding of how to best manage chronic pain.

By signing below, you further attest and agree to have your urine samples available for further study in a research protocol.

Your name and other information that might identify you to outside sources will be removed and an internal patient ID number substituted. This will insure you cannot be identified as connected to the sample by anyone outside of our clinic.

The information will, however, be available to your doctor for benefit of furthering your care.

While the collection of your urine for monitoring is not voluntary, your participation in research to further our understanding of pain management is and you may decline without consequence to your care at the Pain Management Center of Paducah.

O I agree to have my urine samples used for research and education.

O I decline to have my urine sample used for research and education.

Name

Date

Witness

Date 


\section{APPENDIX III}

\section{PROTOCOL SUMMARY}

Brief Title:

Chronic Pain Patients

Official Title:

Study Type:

FDA Regulated Intervention:

IND/IDE Protocol:

Sponsor:

Collaborators:

Responsible Party:

Review Board:

Oversight Authorities:

Brief Summary:

\section{Detailed Description:}

Record Verification Date:
Accuracy of Point of Care (POC) or In-office Urine Drug Testing (Immunoassay) in Chronic Pain Patients: A Prospective Analysis of Immunoassay and Liquid Chromatography Tandem Mass Spectometry (LC/MS/MS)

A diagnostic accuracy study of urine drug testing.

No

No

Pain Management Center of Paducah

Ambulatory Surgery Center, Millennium Laboratories

Name: Laxmaiah Manchikanti, MD

Official Title: Medical Director

Organization: Pain Management Center of Paducah

Phone: 270-554-8373

Approval Status: Approved

Approval Number: Protocol 26

Board Name: Institutional Review Board of Ambulatory Surgery Center Phone: 270-554-8373

E-mail: clinicaldirector@thepainmd.com

United States: Institutional Review Board

To compare the information obtained by POC in-office testing (index test) to the information found when all drugs and analytes are tested by LC/MS/MS (reference test) in the same urine sample.

To correlate clinical factors in relation to threshold levels, prevalence of abuse, false-positives, false-negatives, influence of other drugs, and demographic characteristics.

Recruitment is indicated in patients with chronic pain management with or without controlled substance therapy.

This is a diagnostic accuracy study performed in an interventional pain management referral center in the United States.

The study involves 1,000 patients.

Performed in pre-enrollment phase 
APPENDIX III - continued

\section{Overall Status:}

Study Start Date:

Primary Completion Date:

Study Completion Date:

Study Design:

Outcome Measures:

Conditions:

Key Words:

Interventions:
Enrolled by invitation

February 1, 2010

Recruitment completion by June 30, 2010 (anticipated)

Study completion June 30, 2010 (anticipated)

Patients will be recruited continuously. All urine is tested in each patient with an index test and confirmed by a reference test in a double blind fashion with subject and caregiver being blinded to the results.

Index test is performed in the office utilizing immunoassay; whereas the reference test - LC/MS/MS - is performed at Millennium Laboratories.

Diagnostic accuracy study

Primary Purpose: Diagnostic accuracy

Study Phase: N/A

Intervention Model: Continuous assessment

Number of Arms: One

Masking: Double-blind (Subject, Caregiver)

Allocation: All urine is tested with an index test and confirmed by a reference test

Control: Diagnostic accuracy, none utilized

Endpoint Classification: Accuracy of urine drug testing

Enrollment: 1,000 (anticipated)

Primary Outcome Measure: Diagnostic accuracy

Time Frame: 72 hours

Safety Issue: No safety issues

Patients with chronic pain management with or without controlled substance therapy.

Controlled substances

Opioids

Benzodiazepines

Illicit drugs

Immunoassay drug testing

Point of care (POC) testing

Liquid Chromatography Tandem Mass Spectometry

Index Text: In-office Urine Drug Testing (Immunoassay) in Chronic Pain Patients

Reference Test: LC/MS/MS Laboratory Evaluation 
APPENDIX III - continued

Eligibility Criteria:

Inclusion criteria:

- Chronic pain management with or without controlled substance therapy.

Exclusion criteria:

None

Gender: Both

Minimum Age: $\quad 18$ years

Maximum Age: $\quad$ No limit

Accepts Healthy Volunteers? No

Central Contact: Laxmaiah Manchikanti, MD

Phone: 270-554-8373 Ext. 101

E-mail: drlm@thepainmd.com

Study Official/Investigator: Laxmaiah Manchikanti, MD

Study Principal Investigator

Location: Facility:

Pain Management Center of Paducah, Paducah, KY

Ambulatory Surgery Center, Paducah, KY

Contact: Laxmaiah Manchikanti, MD 